\title{
Learnings from an Open Science Effort: Virtual Project on the History of ALD
}

\author{
R. L. Puurunen \\ Aalto University, School of Chemical Engineering, \\ Department of Chemical and Metallurgical Engineering, Finland
}

This work summarizes learnings from an Open Science effort "Virtual project on the History of ALD" (VPHA), started in 2013 to clarify the early history of atomic layer deposition (ALD). ALD is a multi-tool of nanotechnology and has been e.g. enabler of the continuation of Moore's law of transistor scaling. ALD has been developed historically through two independent routes: atomic layer epitaxy (ALE) and molecular layering (ML). Especially the details on ML have remained little known to a broader audience. In this contribution, learnings in VPHA are seen from the viewpoint of its voluntary coordinator (the author self) related to historical details of ALD as well as from an organizational viewpoint and some other viewpoints. Selected details related to ALD's history not fully accurately described in three earlier review articles are pointed out. The work made in VPHA has resulted in journal articles, presentations and an exhibition, and VPHA has in part provided the foundation for granting the 2018 Millennium Technology Prize to Dr. Tuomo Suntola. At the time of writing this contribution, in July 2018, VPHA is still on-going, and more volunteers are welcome to join the effort.

\section{Introduction}

Atomic layer deposition (ALD) is a materials growth method belonging to the general class of chemical vapor deposition (CVD) techniques. In ALD, utilizing repeated, separate self-terminating gas-solid reactions of compatible compounds [1-4], thin uniform material layers can be grown on three-dimensional topographies of unprecedented complexity [5,6]. ALD is has in the past decade been a core enabler of the continuation of Moore's Law of transistor miniaturization [7]. As a true multi-tool of nanotechnology, interest in ALD keeps on growing to new application areas, which is seen in growth of scientific [8] and patent literature [9]. Recently, the Finnish inventor of ALD, Dr. Tuomo Suntola, was awarded the prestigious 2018 Millennium Technology Prize (MTP) for his development of the ALD technology [10-12].

This contribution is related to the authors's invited talk at the 234th ECS /AiMES Meeting, ALD Applications 14, symposium G01, to be held Sept. 30-Oct. 4, 2018 in Cancun, Mexico. The work deals with learnings from the on-going open science effort started in 2013 called "Virtual project on the History of ALD" (VPHA), initiated by the author with three others, and voluntarily coordinated by the author. The principles of ALD have been developed independently twice, under the names "atomic layer epitaxy" (ALE) and "molecular layering" (other names have sometimes been used, too). Especially the details related to the ML branch of ALD have remained little known to a broader audience. VPHA, which has a dedicated website (http://vph-ald.com) and a 
related blog (http://aldhistory.blogspot.fi), aims to clarify the early details of ALD development. Indeed, VPHA started from a question, asked in LinkedIn: "What are the 'Molecular layering' papers by Koltsov from 'early 1960's'?” [13]. From within VPHA, so far three review-type articles have been published: an essay on ALE [14], an essay on ML [15], and a recommended reading list of twenty-two early ALD works [16]. Additionally, several conference presentations [17] have been prepared, an exhibition " 40 Years of ALD in Finland - Photos, Stories (FinALD40)" [18] created, and updates to several ALD-related Wikipedia pages made. Suntola's MTP nomination was written in July 2017 by the author as a natural continuation of the VPHA activities [19]; the materials created in VPHA provided a solid foundation for it. At the time of writing the current contribution, July 3, 2018, VPHA has in total 76 contributors from 21 countries in four continents. VPHA is still on-going and more volunteers are welcome to join.

In this contribution, the learnings from VPHA are dealt with from the coordinator's viewpoint related to (i) the history of ALD, (ii) coordinating an open science effort like VPHA, and (iii) yet other viewpoints. Additionally, (iv) some pieces of information related to the history of ALD published in earlier ALD reviews, where attention is needed related to the correctness of the details reported, are pointed out.

\section{Methods - how VPHA works}

To facilitate the collection and sharing of information on scientific and patent publications on the early history of ALD (up to 1986) in VPHA, an openly accessible, cloud-based document (Google docs) called ALD-history-evolving-file has been set up [20]. The ALD-history-evolving-file contains the following parts: Introduction and invitation to participate in VPHA (published also separately [21] as electronic supplementary information to Ref. 16); Instructions on how to participate in VPHA; List of early literature on ALD, with comments on the significance of the works by individual contributors; and List of contributors. The ALD-history-evolving-file is open for everyone to view and leave non-anonymous comments to individual articles. Those who give at least one comment in the ALD-history-evolving-file, become VPHA contributors.

To enable the VPHA, materials have been made available through the dedicated VPHA website [22]. A related blog by the author, called the ALD History Blog [23] (with a related Twitter account, @aldhistoryblog), helps to distribute information on VPHA and other ALD history related aspects and to store VPHA communications in an open manner. VPHA status updates are sent as needed via email to all contributors and prospective contributors (those who have actively expressed their interests to become a contributor), with recipient addresses in the bcc: field. Copies of these status updates, with optionally sensitive information removed (marked with $<_{\ldots} .>$ ), can be found behind one link in the ALD History Blog [24] for the status updates sent since the initiation of the blog. 


\section{Results and Discussion: Learnings from the VPHA}

Learnings on the history of ALD, atomic layer epitaxy side

Finding out the details of ALD in Finland was initially not a central goal in VPHA when it was started in summer 2013. However, when the author met Dr. Tuomo Suntola for the first time related to the VPHA on October 16, 2013, the author understood that it is not only that we do not know details of the ML side of ALD: many of the details that Suntola told as self-evident for him, were new to the author. The author has worked with ALD since 1998 and has had an interest in the history of ALD. If these details were new to the author, they had to be new to a large portion of the ALD community, too. The author started writing things down.

The meeting with Suntola, and the trip to St. Petersburg in November 2013 (see next section), motivated the author to write down the history of ALE-ALD in Finland and create an exhibition "40 Years of ALD in Finland - Photos, Stories (FinALD40)" $[18,25]$ (the latter jointly with the University of Helsinki, Dr. Jaakko Niinistö). The exhibition was originally created for the International Baltic ALD conference, Helsinki, May 12-13, 2014. Later, the exhibition travelled also to the international ALD 2014 conference in Kyoto, where the author also gave an invited tutorial on the history of ALD [26]. The ALE story, originally part of the FinALD40 exhibition, was published in October 2014 in the CVD journal [14]. On November 29, 2014, exactly forty years after applying the first ALE patent, the materials of the FinALD40 exhibition were released and published as a merged pdf file through the ALDCoE and VPHA websites [18,25].

By way of example, some information is presented here, which came to the author as new when discussing with Suntola related to early history of ALE-ALD, of which presumably most people in the ALD community likewise were unaware of. For more details on these and other aspects, the reader is referred to the e.g. the ALE essay [14], the FinALD40 exhibition materials [18,25], and the recommended reading list of early ALD literature [16].

- Several spatial ALD concepts were presented in the patents by Suntola and coworkers in the 1970s.

- The first conference presentation of ALE by Suntola in 1980 with a demonstration of an electroluminescence display prototype was a sensation that gathered massive attention through over 3000 product inquiries.

- The second conference presentation by Suntola in 1981 was less successful, with the name of the technique (the epitaxy) partly questioned. Nevertheless, this appearance laid the seeds for ALE development in Japan.

- The first demonstrator of electroluminescent ALE-EL displays since 1983 at the Helsinki airport worked continuously for fifteen years, without the need to replace one single character module.

- The ALE-EL technology was licensed in the early 1980s to France to the stateowned company CGE. ${ }^{1}$

- Academic ALD research in Finland was fully related to electroluminescent displays as application during up to mid-1980s.

- ALD was used for photovoltaic applications already in the end of 1980s.

\footnotetext{
${ }^{1}$ Compagnie Générale d'Electricité, later part of Alcatel.
} 
Learnings on the history of ALD, molecular layering side

Finding out the details of ALD in USSR/Russia was a core goal when setting up VPHA. Indeed, the whole VPHA originally started from a question related to the early ML works [13].

In addition to having volunteers in VPHA to read and comment on the early publications, it was important to be in contact with the original ML-ALD researchers in St. Petersburg. At the time of initiating the VPHA, the two persons credited for originally developing ML-ALD, professors Aleskovskii and Koltsov, were already deceased. Prof. Anatoly Malygin and Prof. Victor Drozd were among the closest followers of these persons at the two historical ALD groups in two different universities. They were the ones to know the best, how the development of ML-ALD took place. They were contacted, and both were helpful. (Malygin had, ten years earlier, already helped the author to start gathering information for my 2005 review [3].)

Conveniently, the author was invited to speak at the opening seminar of the Beneq company's "AppLab" opening in St. Petersburg on November 15, 2013, where the local ALD people gathered. During this trip, the author for the first time met Malygin and Drozd and many other local ALD-related people, and visited five (!) local research groups with ALD activities. The trip was of core importance to have a good start for the VPHA. During this trip, the author received, with permission, copies of (parts of the) theses of Aleskovskii and Koltsov [27,28], which are two core references related to the development of ML-ALD. To the authors's knowledge, researchers from the ALE branch of ALD had not had access to these works before.

The author went to St. Petersburg in November 2013 with a long list of questions on ML-ALD. Since then, many of those questions have received answers, and many of those answers have been written down in the ML essay by Malygin et al. [15] and in the recommended reading list of early ALD publications [16]. In the next bullets, some things are described which the author personally has learnt on ML-ALD, which likely have been new to most people in the ALD community. For further details on these and other matters, the reader is referred to the ML essay [15], a VPHA poster on ML [29] and to the plenary talks by Drozd and Malygin at the Baltic ALD 2014 and the ALD 2016 conferences in Helsinki and Dublin [30,31].

- The oldest so far confirmed written record of ML dates back to 1965 to a brief local meeting abstract [32].

- Atmospheric pressure was used in many of the early ML studies. The information is typically not written out in the publications themselves.

- The first USSR patents on ALD for catalysis date from 1972 (they were published in 1974. Example in Ref. 33.

- Thin film growth in mid-1970s. Information on thin film reactors built by Drozd; first reports on materials such as $\mathrm{HfO}_{2}$ from $\mathrm{HfCl}_{4}$ and $\mathrm{H}_{2} \mathrm{O}$.

- Early catalysis ALD works in Bulgaria [34].

- Amine-catalysed $\mathrm{SiO}_{2}$ process.

- In situ gravimetry during ALD process.

- Small-scale production by ML-ALD.

- Use of fluidized bed for particle coating. 
- Massive list of PhD theses of ML-ALD.

- Prof. Valentin Aleskovskii's role in the academy: Aleskovskii has founded two ML-ALD groups at two universities and acted as rector of both universities.

- The central role of the ML thesis of Prof. Koltsov for ML-ALD. Still in the 2010s, this thesis is a core reference and source of inspiration in ML-ALD.

When did the ALE and ML researchers meet for the first time?

When starting the VPHA, one of the questions the author had in mind was: how did the ALE and ML researchers actually meet for the first time? Asking the local ALD colleagues, the answer was repeatedly that "they just appeared at the ALE- 1 conference" [35]. This was puzzling: how come they "just appeared"? Before one can appear at an event, one has to know of it? How did they know of ALE-1 in the first place?

This puzzle found its missing pieces through discussions with the persons who came to the ALE-1 conference from Russia and Estonia, Viktor Drozd and Jaan Aarik, respectively. The person who had played a central role in spreading the information, had been Prof. Markus Pessa, from Tampere University of Technology. Pessa had met both persons in Tallinn university at fall workshop on MBE-MEE technology in the end of October 1989 and shared information of the event to come. Prof. Lauri Niinistö had further helped the two with practical organizations of the trip. The meeting at ALE-1 has been described in both the ALE [14] and the ML essays [15]. Further details have been described in a post in the ALD History Blog, which has also comments included by Drozd and Aarik [36].

Details on the history of ALD published in earlier reviews, which need attention

There are three review articles, which are important in the ALD field in their own ways, related to which the current author would like to take the opportunity to draw attention to with respect to details of their ALD history descriptions. These review articles have been published in 2005 [3], 2010 [4], and 2013 [38].

The 2005 review [3]. This review by Puurunen (the current author) is currently the world's second most cited review on ALD (1284 citations as of July 1, 2018, WoS). The 2005 review was the first review article written in English, where both the ALE and the ML origins of ALD were described, and which has reached a broad audience. In Ref. 3, to specifically shed light on the ML-ALD works, a separate table (Table 1) was prepared, which collects information on the variety of the ML works. It should be noted that there is, however, an earlier ALD review article in English, which also describes both origins and which deserves attention: it is a review article by Aarik, published in Estonian conference proceedings in 1990 [37].

In the 2005 review, there is one small factual mistake included, which needs to be corrected. The 2005 review [3] says (page 3): "Connection between the groups has been established already in the late 1980s, however, and scientists of the two groups have even met." Source of the information was an oral presentation at the ALD 2004 conference (Ref. 74 in [3]). With comparisons and fact-checking made by the author in multiple 
personal discussions and the two essays written on the history of ALD [14,15], it can be concluded that the first contact between the major ALE and ML scientists did not quite yet take place at the end of 1980s, as the 2005 review states, but at the first International Symposium on Atomic Layer Epitaxy (ALE-1) in Espoo in June 1990 [36].

The 2010 review [4]. This review by George is currently the world's most cited ALD review (2117 citations as of July 1, 2018, WoS) and thereby highly influential in the field. What comes to the history of ALD, the facts reported in the article are to the current author's understanding correct. Related to this article, noteworthy related to understanding the history of ALD is, what is not reported. The 2010 review does not mention the ML-ALD branch of ALD.

The 2013 review [38]. This review by Parsons et al. describes, among other things, how the international ALD conference series by the AVS started. Positively, ML is mentioned as an origin of ALD. In the 2013 review, as items needing attention, the current author has recognized the following three.

\#1. The 2013 review [38] tells that ALD was described already in Aleskovskii's thesis in 1952: "The concept of molecular layering was first proposed by Prof. V. B. Aleskovskii in his Ph.D. thesis published in 1952." (No reference is given as source of the information.) First, the thesis of Aleskovskii in 1952 [27] was not equivalent to a $\mathrm{PhD}$; rather, the thesis is known as a "habilitation degree" or "doctor of science thesis" or perhaps "professor's thesis". Second, ALD or ML was not yet described in the thesis [27]; instead, an idea called the "matrix hypothesis" or "skeleton hypothesis" was described. This hypothesis, summarized in Figure 7 of [15], has according to Russian ALD researchers [15] been an essential step for the development of the ML method. Still, the hypothesis is not recognizable as ALD yet: for example, there are no reaction cycles involved.

Wikipedia had contained similar information related to the thesis of Aleskovskii as published in the 2013 review for several years. One can find out from the page history that this information was added on 31 January 2011 [39] and was there still on 23 January 2016 [40]. On 24 January, 2016, in a VPHA-related Wikipedia updating activity, a major revision of the history description of the ALD page was made [41,42]. In this revision, the statement related to Aleskovskii's thesis was modified, to acknowledge the thesis as a source of the "matrix hypothesis" only, and not of ML-ALD.

\#2. The 2013 review [38] tells that "the ALD principle, where surface reactions follow a binary sequence of self-limiting half-reactions, was first published under name "molecular layering" in the early 1960s by Prof. S. I. Kol'tsov from Leningrad Technological Institute." Two sources are given as references (Refs. 2 and 3 in [38]); however, neither of the references directly supports the statement, as they are both from later years (1968 and 1969). Similarly as for Item \#1 above, the page history of Wikipedia shows that similar information appeared on the Wikipedia ALD page on 31 January 2011 [39] and it stayed there until the VPHA-related Wikipedia updating activity took place [41,42]. As noted in the list of learnings from VPHA on ML-ALD earlier in this contribution, and as reported in the VPHA recommended reading list [16], the earliest written record of ML-ALD so far found and confirmed is a short conference 
abstract from 1965 [32]. Thus, to the best current knowledge, the first ML-ALD publication is not from early 1960s, but from mid-1960s.

\#3. The 2013 review [38] leads one to think that ML research did not involve research on planar substrates. The review says: "a planar thin film was not produced or evaluated." Information on planar thin film experiments by ML-ALD have, however, been easily available since the publication of the 2005 review [3]. The ML essay [15] and the VPHA 2017 review [16] further point to original sources of studies of planar films.

Learnings on the organization of the VPHA as an Open Science project

Professional social media is an enabler. The VPHA started from a question in LinkedIn [13], which resulted in a lively discussion that planted the seeds of the future VPHA. Had there not been a community of ALD researchers to reach through one channel (this particular LinkedIn group) this way, there would have been not the kind of discussion and no VPHA as we know it. (There could have been something else instead, at another time - what, we will not know.) Professional social media in part enabled the VPHA and can undoubtedly enable (and likely has enabled) other international open collaborations.

Crazy ideas can be the most valuable ones. VPHA started from a "crazy idea." After it was clear that there are still open questions related to the history of ALD in spring 2013 [13], eight years after the 2005 review [3] was published, the idea came to the author: could we facilitate "the whole ALD community" to work together to clarify the open questions on the history of ALD? On the 2005 review [3], the author had worked mostly alone. These open questions were, after all, relevant for everyone working in the field; could answer them together? The author had had just participated in a course on facilitation methods, none of which were directly applicable to VPHA, but which gave ideas of how to proceed. With help of interested initial collaborators, we found a way to start.

Diversity is beneficial. In VPHA, and probably in many other volunteer-based projects, the best result is gained when we have people from different background with different knowledges and skills. For having a balanced description of the history of ALD we have clearly benefited from having different types of people involved: young researchers, experienced researchers, people from different fields and geographical backgrounds, people with different language skills.

Openness is an asset. From very early on, we decided to carry out VPHA in an open way, as the VPHA slogan says: in atmosphere of Openness, Respect, and Trust. Only later did we notice that the way VPHA is carried out is well in line with Open Science principles in general [43] and with many of the underlying philosophies of Wikipedia [44]. Openness has helped to spread information effectively, avoided duplicate work by people, and dimished the need for unproductive internal communications.

Without active coordination, things won't proceed. VPHA has had periods of active work and periods of almost no (visible) work. When there has been active coordination, 
distribution of work, and deadlines, VPHA has progressed. In the lack of such coordination, little visible progress has happened.

Here, the author would like to note, though, that from her personal perspective, there has been some progress going on practically all the time, which may not have been visible to the average VPHA contributor. Work in the background has been made for the ALE and ML essays, as well as the Millennium Technology Prize nomination, and now latest for this contribution.

The Bcc field is our friend. Many of us have been involved in lengthy "email chats", where people "reply to all" in a list of tens of recipients, reporting details which are relevant to a small fraction of the recipient list. The emails sent in VPHA, with often over a hundred recipients, have all been sent with recipient addresses in the Bcc (blind carbon copy) field. Unnecessary email chats have been avoided.

Simple is elegant and likely sufficient. When we started, there was the big question: how to organize the collection of information on the early works on ALD, and the comments on them by the contributors. Basically one file, the ALD-history-evolving-file [20], came up as the solution, with a structure as simple as we could think of: reporting the historical article, and the contributor's comments thereafter. (We do have a "sister document" to keep track of the number of comments per entry.) Each contributor has one place to say what he/she wishes to say. In hindsight, the simple solution has worked well: this one file has served the VPHA already for approximately five years.

"Openness, Respect, and Trust" is a useful guideline. The initial setting that was decided for VPHA, that is, "to be carried out in the atmosphere of Openness, Respect, and Trust," has been a valuable guideline. The author acknowledges to have personally relied on this guideline at several occurrences during the VPHA, when unexpected turns took place and it was difficult to know how to proceed. These guidelines might be valuable to adopt in some other future activities as well.

It may take longer than you think. VPHA was started in summer 2013; five years later, it is still on-going. If someone had told the author five years ago that she would be still working with the same subject, she would not have believed. (She also would not have believed that the Millennium Technology Prize would be granted.) VPHA has taken more time than we could have imagined. But: good things take their time. Haste only makes waste.

\section{Other learnings}

History is emotional. It has become clear that the history of ALD is an emotional subject. The author remembers her own mixed feelings, when she learnt (likely in 2003) that (i) ML is the same as the ALD that she knew and (ii) the first ML works are older than the first ALE works. Accepting a new reality was a process that took time - and in the author's case, resulted in a review article [3]. The author has seen other people become emotional related to the history of ALD, too. Hopefully, the jointly collected facts will calm some emotions. ALD has become so large that no-one has the full picture 
of the field anymore. Of the historical publications, we can at least have the same list of references.

Our background affects our thinking. It would be inviting to think that scientists always think objectively. However, having been exposed to different facts and looking at a matter from different viewpoints, people are bound to see the big picture differently. By collecting together and sharing facts in VPHA, we have aimed to help people understand each other better and see more of the same picture.

Someone will oppose. The author has learnt, in VPHA as well as other activities, that one cannot make all people happy and there will always be people who oppose what you (plan to) do. Sometimes, one can inversely interpret the opposition as support for one's cause: nobody cares to actively oppose unimportant things. The author is grateful that with the support of many VPHA collaborators and with continued support of Suntola, she has been able to lead and coordinate VPHA up to a point where its value has become generally recognized.

Scientists want to and deserve to be cited. The reputation of a scientist gets built from recognition by peers citing their works. The author has encountered in the field of ALD people frustrated when their work has not been cited when it obviously should have been, collectively looking past ML as an origin of ALD being the most significant such case. Indeed, during the November 2013 trip to St. Petersburg, the first question after one of the presentations by the author was, by a seasoned local ALD scientist (approximately like this): "Why have our works not been cited?"

Citing earlier works is a deep underlying ethical principle of science. While mistakes happen and the author does not claim to have made none herself, the author wishes that in the field of ALD we would in the future more carefully pay attention to giving credit to others by citing works with relevance to ours. The research integrity guidelines binding Finnish research organizations say [45, p. 30]: "The researcher takes due account of the work and achievements of other researchers by respecting their work, citing their publications appropriately, and by giving their achievements the credit and weight they deserve in carrying out the researcher's own research and publishing its results."

Original written sources are the most valuable. Oral recollections by a person carry a significant uncertainty factor. Statements based on secondary sources (author xxx cites that work yyy reported that...) carry a significant uncertainty factor. It is always best to look up original written sources.

Statements are best made on what others did, not on what (we think) they did not do. Related to the ML-ALD origin, there have been many "negative" statements made, stating what was presumably not done. But how can we know what others did not do? Positive statements can be supported with references, but how to support negative statements? What if we just don't know? Especially if we didn't try to find out, we should not think that we know.

How to cite articles, originally in Russian (or other) and translated into English? Many of the early scientific ML-ALD articles have been published originally in Russian and officially translated in English one to two years after publication. The author has since 
the 2005 review article adopted the practice to cite both versions: both the Russian original, and the English translation; the review [3] contains many examples. An example of the review article by Aleskovskii in 1974 is shown in Ref. 46.

Citing Wikipedia. Wikipedia has emerged as a source of information openly available to everyone. We all can write in Wikipedia. In science, Wikipedia is typically sparingly used, one reason being that the correctness of the information is not guaranteed. Still, there are many pages which are excellent in contents (and of course some that are not). Personally, the author is of the opinion that Wikipedia can be used as a source, with caution, and citing it accurately. Page history is stored in Wikipedia, so it should be sufficiently accurate to cite by the page name and link, adding a note such as "accessed day xx, Month, Year". Another way is to refer to a permalink of the page one was using; many such permalinks are included in the reference list of this work [39-41]. Wikipedia has further instructions on how the contents can be reused [47].

\section{Conclusion}

In this work, learnings have been overviewed from the VPHA ALD history project from various viewpoints: related to the history of ALE, related to the history of ML, related to how the two branches of ALD have merged, related to Open Science, and yet some other general viewpoints. In addition, the author has pointed out and attempted to set straight some details on the history of ALD, which were not fully accurately described in earlier review articles.

VPHA has been - and continues to be, as more volunteers are still welcome - a unique Open Science activity. In hindsight, in the author's personal view, VPHA has been a needed activity in the field of ALD. Learnings in VPHA have not only been related to the historical details on ALD, but also on how to organize an international Open Science project, and perhaps a bit on how the human nature works, too. Hopefully some of these learnings, which have been overviewed in the previous sections, can be useful for other Open Science efforts and other endeavors in the future.

To end, the author likes to share a quote by Aristotle, which she has learned is one of Dr. Tuomo Suntola's favourites. With this quote, Suntola personalized a copy of his book [48] to the author in October 2013, when meeting for the first time related to the VPHA ALD history activities. The quote (given originally in Finnish, and translated) compactly summarizes what the VPHA is all about.

\section{“ Ihmisellä on halu tietää. - All men by nature desire to know. "}

\section{Acknowledgments}

First, the author wishes to thank all contributors of VPHA. It has been great that so many have volunteered: each contribution matters. The VPHA contributors are, as of June 6, 2018: Jaan Aarik, Esko Ahvenniemi, Andrew R. Akbashev, Saima Ali, Mikhael Bechelany, Maria Berdova, Ivan Bodalyov, Stefan Boyadjiev, David Cameron, Nikolai Chekurov, Rong Chen, Mikhail Chubarov, Veronique Cremers, Anjana Devi, Viktor 
Drozd, Simon Elliott, Liliya Elnikova, Gloria Gottardi, Aristeidis Goulas, Kestutis Grigoras, Dennis Hausmann, Cheol Seong Hwang, Marcel Junige, Shih-Hui Jen, Tanja Kallio, Jaana Kanervo, Ivan Khmelnitskiy, Do Han Kim, Lev Klibanov, Yury Koshtyal, Outi Krause, Jakob Kuhs, Irina Kärkkänen, Marja-Leena Kääriäinen, Tommi Kääriäinen, Luca Lamagna, Adam Lapicki, Markku Leskelä, Harri Lipsanen, Jussi Lyytinen, Anatoly Malkov, Anatoly Malygin, Abdelkader Mennad, Christian Militzer, Jyrki Molarius, Małgorzata Norek, Cagla Ozgit-Akgun, Mikhail Panov, Henrik Pedersen, Luis Fabián Peña, Fabien Piallat, Georgi Popov, Alexander Pyymaki Perros, Geert Rampelberg, Robin H. A. Ras, Erwan Rauwel, Fred Roozeboom, Timo Sajavaara, Hossein Salami, Hele Savin, Nathanaelle Schneider, Thomas E. Seidel, David C. Smith, Pia Sundberg, Jonas Sundqvist, Dmitry Suyatin, Massimo Tallarida, Tobias Törndahl, Mikko Utriainen, J. Ruud van Ommen, Thomas Wächtler, Timo Weckman, Claudia Wiemer, Oili M. E. Ylivaara, Oksana Yurkevich.

The author is grateful to Dr. Tuomo Suntola for support on her ALD history activities throughout the years; and to Dr. Jonas Sundqvist for creating and keeping lively the ALD - Atomic Layer Deposition LinkedIn group as well as for his enabling support in the VPHA ever since its planning phase. The author would like to acknowledge Dr. Aziz Abdulagatov and Annina Titoff for help with initially setting up the VPHA. Mikko Kaarela invited the author to the Beneq AppLab opening event in November 2013. Thanks to Dr. Jonas Sundqvist and Dr. Angel Yanguas-Gil for their help with ALDrelated Wikipedia pages; to Prof. Mato Knez, Prof. Robin Ras and Prof. Ruud van Ommen for valuable discussions related to this manuscript; and to Prof. Sean Barry for many useful discussions during the years.

Prof. em. Michael Hitchman, editor of the CVD journal, actively helped to get the ALE and ML essays published. Support by the JVSTA journal through granting an Open Access status for the VPHA 2017 review is gratefully acknowledged.

VPHA has not had any direct funding. Still, I would like to thank the Academy of Finland for support, as the VPHA was created within the Finnish Centre of Excellence on ALD; and the HERALD COST network (MP1402) for general support.

\section{References}

1. T. Suntola, Atomic layer epitaxy, Mater. Sci. Reports, 4, 261-312, (1989). DOI: $\underline{10.1016 / \mathrm{S} 0920-2307(89) 80006-4}$

2. M. Ritala and M. Leskelä, Atomic layer deposition, in Handbook of Thin Film Materials, edited by H. S. Nalwa (Academic Press, San Diego, 2002), vol. 1, pp. 103-159.

3. R. L. Puurunen, Surface chemistry of atomic layer deposition: a case study for the trimethylaluminum/water process, J. Appl. Phys., 97, 121301 (2005).

DOI: $\underline{10.1063 / 1.1940727}$

4. S. M. George, Atomic layer deposition: an overview, Chem. Rev., 110, 111-131 (2010). DOI: $10.1021 / \mathrm{cr} 900056 \mathrm{~b}$

5. J. Elam, D. Routkevitch, P. P. Mardilovich, S. M. George, Conformal Coating on Ultrahigh-Aspect-Ratio Nanopores of Anodic Alumina by Atomic Layer Deposition, Chem. Mater., 15, 3507-3517 (2003). DOI: 10.1021/cm0303080 
6. F. Gao, S. Arpiainen, R. L. Puurunen, Microscopic silicon-based lateral highaspect-ratio structures for thin film conformality analysis, J. Vac. Sci. Technol. A, 33, 010601 (2015). DOI: $10.1116 / 1.4903941$

7. M. T. Bohr, R. S. Chau, T. Ghani, K. Mistry, The high-k solution, IEEE Spectrum, 33, 29-35 (2007). DOI: 10.1109/MSPEC.2007.4337663

8. E. Alvaro, A. Yanguas-Gil, Characterizing the field of atomic layer deposition: authors, topics, and collaborations, PLOS One, Jan 10, (2018).

DOI: $10.1371 /$ journal.pone.0189137

9. BALD Engineering Blog by Sundqvist, April 1, 2018: "ALD research and development continuous growth!"

http://www.blog.baldengineering.com/2018/04/ald-research-and-developmentcontinious.html. Accessed July 6, 2018.

10. Technology Academy Finland press release, May 22, 2018, “2018 Millennium Technology Prize for Tuomo Suntola - Finnish physicist's innovation enables manufacture and development of information technology products." Link: https://taf.fi/2018/05/22/2018-millennium-technology-prize-for-tuomo-suntolafinnish-physicists-innovation-enables-manufacture-and-development-ofinformation-technology-products/. Accessed June 29, 2018.

11. ALD History Blog by Puurunen, May 23, 2018: "Congratulations Dr. Tuomo Suntola for the 2018 Millennium Technology Prize!" http://aldhistory.blogspot.com/2018/05/congratulations-dr-suntola-formillennium-prize.html. Accessed June 29, 2018.

12. ALD History Blog by Puurunen, May 27, 2018, "Dr. Suntola thanks the community for support and shares honor for the 2018 Millennium Technology Prize," http://aldhistory.blogspot.com/2018/05/suntola-thanks-community-forsupport-and-shares-honor.html. Accessed June 29, 2018.

13. LinkedIn discussion chain initiated by Puurunen, 6 May 2013, in the group "ALD-Atomic Layer Deposition," entitled "What are the 'Molecular layering' papers by Koltsov from 'early 1960's'?”

https://www.linkedin.com/groups/1885076/1885076-238399494. Accessed July 1, 2018.

14. R. L. Puurunen, A short history of Atomic Layer Deposition: Tuomo Suntola's Atomic Layer Epitaxy, Chem. Vap. Deposition, 20, 332-344 (2014).

DOI: $\underline{10.1002 / \text { cvde.201402012 }}$

15. A. A. Malygin, V. E. Drozd, A. A. Malkov, V. M. Smirnov, From V. B. Aleskovskii's "Framework" Hypothesis to the Method of Molecular Layering/Atomic Layer Deposition, Chem. Vap. Deposition, 21, 216-240 (2015).

DOI: $\underline{10.1002 / \mathrm{cvde} .201502013}$

16. E. Ahvenniemi, A. R. Akbashev, S. Ali, M. Bechelany, M. Berdova, S. Boyadjiev, D. C. Cameron, R. Chen, M. Chubarov, V. Cremers, A. Devi, V. Drozd, L. Elnikova, G. Gottardi, K. Grigoras, D. M. Hausmann, C. S. Hwang, S.-H. Jen, T. Kallio, J. Kanervo, I. Khmelnitskiy, D. H. Kim, L. Klibanov, Y. Koshtyal, A. O. I. Krause, J. Kuhs, I. Kärkkänen, M.-L. Kääriäinen, T. Kääriäinen, L. Lamagna, A. A. Lapicki, M. Leskelä, H. Lipsanen, J. Lyytinen, A. Malkov, A. Malygin, A. Mennad, C. Militzer, J. Molarius, M. Norek, Ç. Özgit-Akgün, M. Panov, H. 
Pedersen, F. Piallat, G. Popov, R. L. Puurunen, G. Rampelberg, R. H. A. Ras, E. Rauwel, F. Roozeboom, T. Sajavaara, H. Salami, H. Savin, N. Schneider, T. E. Seidel, J. Sundqvist, D. B. Suyatin, T. Törndahl, J. R. van Ommen, C. Wiemer, O. M. E. Ylivaara, O. Yurkevich, Review Article: Recommended reading list of early publications on atomic layer deposition-Outcome of the "Virtual Project on the History of ALD, J. Vac. Sci. Technol. A, 25, 010801 (2017).

DOI: $10.1116 / 1.4971389$.

17. Publication plan for the Virtual Project on the History of ALD, v3.0, April 5, 2015, http://vph-ald.com/Publication\%20Plan.html. Accessed June 29, 2018.

18. Exhibition by the Finnish Centre of Excellence on Atomic Layer Deposition: "40 Years of ALD in Finland - Photos, Stories" (FinALD40). Exhibition material released to internet 29.11.2014: http://www.aldcoe.fi/events/finald40.html. Accessed July 6, 2018.

19. ALD History Blog by Puurunen, May 25, 2017: "Supporting Letters for Millennium Technology Prize 2018 nomination," http://aldhistory.blogspot.com/2017/05/support-letter-for-millennium-prize.html. Accessed July 6, 2018.

20. ALD-history-evolving-file in Google Docs, direct link to file: https://docs.google.com/document/d/1AlJg29dJM2if4SGzMJSSmwZskCNaAMQ MO9LU6UYPios/. Embedded link can be found through http://vphald.com/VPHAopenfiles.html. Accessed July 6, 2018.

21. Virtual project on the history of ALD: update and invitation to participate, Dated October 25, 2015 (Puurunen, Koshtyal, Pedersen, Van Ommen, Sundqvist); original introduction and invitation to participate dated July 25, 2013 (Puurunen, Abdulagatov, Sundqvist, Titoff). https://avs.scitation.org/doi/suppl/10.1116/1.4971389

22. Website of the Virtual Project on the History of ALD (by Puurunen), http://vphald.com. Accessed July 6, 2018.

23. ALD History Blog (by Puurunen), http://aldhistory.blogspot.com. Accessed July 6, 2018.

24. VPHA status updates in the ALD History Blog: http://aldhistory.blogspot.com/search/label/VPHA\%20status\%20update. Accessed July 6, 2018.

25. R. L. Puurunen, "History of Atomic Layer Deposition," invited tutorial at the International AVS Conference on Atomic Layer Deposition), June 15-18, 2014, Kyoto, Japan. Slides available:

https://www.slideshare.net/RiikkaPuurunen/aldhistory-tutorial-in-kyoyo-aldhistory-tutorialald2014riikkapuurunen20140615. Accessed July 6, 2018.

26. Exhibition by the Finnish Centre of Excellence on Atomic Layer Deposition: " 40 Years of ALD in Finland - Photos, Stories" (FinALD40). Exhibition material released to internet 29.11.2014: VPHA website http://vphald.com/UploadedPublications/FinALD40_web_2014-11-29_update2015-0123.pdf. Accessed July 6, 2018. 
27. V. B. Aleskovskii, "Matrix hypothesis and way of synthesis of some active solid compounds," Thesis for Doctor of Sciences (Habilitation) degree, Leningrad Technological Institute by Lensovet, 1952. (In Russian, English title translated in the VPHA. Original title in Russian: Остовная гипотеза и опыт приготовления некоторых активных твердых тел.)

28. S. I. Koltsov, "Synthesis of solids by the molecular layering method," Thesis for Doctor of Sciences (Habilitation) degree, Leningrad Technological Institute by Lensovet, 1971, 383 p. (In Russian, English title translated in the VPHA. Original title in Russian: Синтез твёрдых веществ методом молекулярного наслаивания.)

29. Poster presentation "On the Early History of ALD: Molecular Layering," by J. Aarik, A. R. Akbashev, M. Bechelany, M. Berdova, D. Cameron, N. Chekurov, V. E. Drozd, S. D. Elliott, G. Gottardi, K. Grigoras, M. Junige, T. Kallio, J. Kanervo, Yu. Koshtyal, M.-L. Kääriäinen, T. Kääriäinen, L. Lamagna, A. Malkov, A. Malygin, J. Molarius, C. Ozgit-Akgun, H. Pedersen, R. L. Puurunen, A. Pyymäki Perros, R. H. A. Ras, F. Roozeboom, T. Sajavaara, H. Savin, T. E. Seidel, P. Sundberg, J. Sundqvist, M. Tallarida, J. R. van Ommen, T. Wächtler, C. Wiemer, O. M. E. Ylivaara, ALD 2014 (14th International Conference on Atomic Layer Deposition), June 15-18, 2014, Kyoto, Japan._http://vphald.com/VPHApublications/VPHA_Kyoto2014_ML-poster_v15_FINAL.pdf. Accessed July 8, 2018.

30. V. E. Drozd, "ML-ALD seeks its niche in education, science and application," invited plenary talk at the $12^{\text {th }}$ International Baltic ALD conference, May 12-13, 2014, University of Helsinki, Finland. Slides: http://vphald.com/UploadedPublications/BALD_Drozd_280ct2014.pdf. Accessed July 7, 2018.

31. A. A. Malygin, "Structural-size effects in the products obtained by the molecular layering method and their application," invited plenary talk at 16th International Conference on Atomic Layer Deposition (ALD 2016), July 24-27, 2016, Dublin, Ireland. Slides: http://vph-ald.com/UploadedPublications/Malygin-ALD201625July.pdf. Accessed July 7, 2018.

32. V. B. Aleskovskii and S. I. Koltsov, "Some characteristics of molecular layering reactions," in Abstract of Scientific and Technical Conference of the Leningrad Technological Institute by Lensovet (Goskhimizdat, Leningrad, 1965), pp. 67-67 (in Russian, English title translated in the VPHA. Original title in Russian: “Некоторые закономерности реакций молекулярного наслаивания").

33. A.A. Malygin, A.N. Volkova, S.I. Koltsov, V.B. Aleskovskii, The method of synthesis of vanadium oxide catalyst for the oxidation of organic compounds (Способ приготовления окиснованадиевого катализатора для окисления органических соединений), Patent \# 422447 (USSR), Date of submission: 31.03.1972, Date of publication: 05.04.1974.

34. D. Damyanov, "Growth by molecular layering of a catalytically active phase on the oxide surfaces" (in Bulgarian), Doctor of Science thesis, Burgas Institute of Technology, Bulgaria, 1987.

35. Proceedings of the ALE-1 conference, chairman: Lauri Niinistö, Acta Polytech. Scand., Chem. Technol. Ser., Vol. 195, Year 1990. 
36. ALD History Blog post February 12, 2017, "ALD history and prof. emeritus Markus Pessa," http://aldhistory.blogspot.com/2017/02/ald-history-and-prof-emmarkus-pessa.html. Accessed July 1, 2018.

37. J. Aarik, Atomic layer epitaxy, Proceedings on Electroluminescence XVIII. Tartu Ülikooli Toimetised 908, Preparation and investigation of thin solid films, Tartu, Estonia 1990, pp. 5-33. http://dspace.ut.ee/handle/10062/32165

38. G. N. Parsons, J. W. Elam, S. M. George, S. Haukka, H. Jeon, W. M. M. Kessels, M. Leskelä, P. Poodt, M. Ritala, S. M. Rossnagel, History of Atomic Layer Deposition and its Relationship with the American Vacuum Society, J. Vac. Sci. Technol., A, 31, 050818 (2013). DOI: 10.1116/1.4816548.

39. Wikipedia: Atomic Layer deposition, edit Jan 31 2011, permalink: https://en.wikipedia.org/w/index.php?title=Atomic_layer_deposition\&direction=n ext\&oldid=404820343.

40. Wikipedia: Atomic Layer Deposition, edit Jan 23, 2016, permalink: https://en.wikipedia.org/w/index.php?title=Atomic layer_deposition\&oldid=7012 $\underline{36079}$.

41. Wikipedia: Atomic Layer Deposition, edit Jan 24, 2016, permalink: https://en.wikipedia.org/w/index.php?title=Atomic layer_deposition\&oldid=7013 $\underline{93909 .}$.

42. ALD History Blog, Jan 25, 2016: "Wikipedia ALD history description updated," http://aldhistory.blogspot.com/2016/01/wikipedia-ald-history-descriptionupdated.html. Accessed Jul 6, 2018.

43. Vicente-Saez, C. Martinez-Fuentes, Open Science now: A systematic literature review for an integrated definition, J. Business Res., 88, 428-436 (2018).

DOI: $\underline{10.1016 / j . j \text { busres.2017.12.043 }}$

44. Wikipedia: Five Pillars, https://en.wikipedia.org/wiki/Wikipedia:Five_pillars. Accessed July 5, 2018.

45. Guidelines of the Finnish Advisory Board on Research Integrity 2012, "Responsible conduct of research and procedures for handling allegations of misconduct in Finland," http://www.tenk.fi/sites/tenk.fi/files/HTK_ohje_2012.pdf. Accessed July 1, 2018.

46. V. B. Aleskovskii, Chemistry and technology of solids, Zh. Prikl. Khim., 47, 2145 (1974) [J. Appl. Chem. USSR, 47, 2207 (1974)].

47. Wikipedia: Reusing Wikipedia contents, https://en.wikipedia.org/wiki/Wikipedia:Reusing_Wikipedia_content. Accessed June 30, 2018.

48. T. Suntola, The Short History of Science - or the long path to the union of metaphysics and empiricism, Physics Foundations Society, Espoo, Finland, September 2012, 292 p. 